\title{
O PORVIR DO GALEGO
}

DOI: $10.17057 /$ fmfhv.2021.008

Texto inédito, conservado en dúas copias mecanografadas con emendas do autor. Datable arredor de 1952, mais concluído en 1954 a petición de Ramón Otero Pedrayo, que o recibe en man no mes de agosto. Arquivo familiar. 

Fálase da vida das lenguas, do seu orixe, das súas loitas, do seu porvir ${ }^{1}$. En moitos casos, estes e outros ditos parecidos non teñen máis que unha sinificación figurada. Pasamos ás lenguas as esperencias que temos dos seres vivos. Está ben feita a comparanza da renovación contina dunha lengua coa renovación dun bosque por outonos e primaveras. Pero pra que resulte xusta, debemos ter en conta que os renovos do bosque son sempre distintos e sempre os mismos e unha lengua non torna nunca a ser igual á si misma.

As lenguas non son seres vivos rexidos por leises inmanentes de proliferación, crecemento e morte dentro de tipos específicos predeterminados por leises de cruces e de herencias. Deixando á parte os orixes do lenguaxe, as lenguas preséntanse no seu proceso histórico en forma de instituciós (Saussure, Meillet). Son independentes de cada individo, pero non viven fora da comunidá, por non seren cousas sustantivas de seu.

Unha lengua non ten comenzo nin fin, se queremos falar con propiedá. No máis íntimo do seu ser está o cambio, a mutación libre, fora de toda liña específica.

Supoñendo algo que hoxe non pode sere, como é o arredamento total dunha comunidá humana aborixe, non se pode concebir a súa lengua sin ter sufrido moitas alteraciós ó cabo dos anos. Os medios de aprensión e trasmisión dunha lengua son suxetivos, tanto polo que se refire á súa sinificación como polo que

1 «O porvir do galego» consérvase en dúas copias mecanográficas — unha parece copia da outra con papel carbón-, unha delas aparece rachada en diversos folios (1, 3, 5 e 6), conservándose destes só unha metade. Sobor desta copia rachada fixera o A. algunhas correccións, aínda que se atopan tamén algunhas na derradeira páxina da conservada enteira. Atópase, tamén, un folio manuscrito onde o A. ameceu algunhas frases. Chamo $1^{a}$ copia o texto non corrixido e $2^{a}$ copia, o corrixido. Non dou conta das correccións feitas polo A. nos acentos e nas comas. As observacións feitas sobre o texto da primeira obra valen tamén para esta segunda que se debeu facer polo ano 1952 tendo en conta a primeira. Manteño o texto do A. coa corrección de "primaveira» en "primaveras» en dúas ocasións e coa conversión — na derradeira volta do seu empregode «expresión» en «espresión» (p. 10), xa que A. corrixira esta palabra un pouco antes e quedaría, se o non fixera, como o único testemuño desta forma [Nota do editor]. 
se refire á súa forma material. Sinos e sinificados non son equivalentes senón hasta certo punto ó pasar de individo a individo e de xeneración á xeneración. Os fillos non reproducen nunca con xusteza a lenguaxe dos pais. As alteraciós que se van sucedendo nunha sociedá pola acumulación de esperencias, novos xiros de sensibilidá, modas, cortesías e cambios de modos e maneiras de sere, todo ven refrexado pola lengua, xa cambiante de seu, que ó cabo dos anos — de moitos anos - acaba por separarse do seu orixe e por dividirse en lenguas comarcals $^{2}$ separadas unha das outras.

Pero as comunidás históricas e as súas lenguas non tiveron este orixe. Son resultado, unhas veces, de amoreamentos de comunidás máis pequenas, coma no caso do Imperio Romano e dos estados renacentistas, aínda en proceso de formación, e de esmigallamentos políticos outras, como acontecéu na derradeira decadencia deste mismo Imperio e noutros moitos casos.

Un instrumento tan sensíbele como é a lengua chega nas dúas situaciós ás alteraciós máis fondas. A maior parte das comunidás humanas hoxe conocidas, sin descontar Galicia, trocaron de lengua unha ou máis veces, sin que o proceso se poida dar por rematado.

No caso de dispersión política, a lengua que foi espresión da unidá, a lengua común, acusa de seguida o fenómeno, ainda que ${ }^{3}$ de moitos xeitos. A razón de que así seña é que as condiciós que se dan nunha escisión política non se repiten noutra e, polo tanto, as consecuencias lingüísticas son sempre novas.

Non hai que pensar, polo pronto, que á unha escisión política corresponda pé por pé unha escisión lingüística, pola mutación da lengua común, uniforme, en tantas variantes como unidás políticas se formen. Nin se dá o caso dunha lengua común sin variantes nos grandes amoreamentos políticos, nin éstas nacen de seu coa división política.

A lengua común chámase así porque se superpón ás variantes lingüísticas escondidas por debaixo da súa uniformidá. Estas variantes rexurden tan axiña como a lengua común deixa de ser espresión dunha comunidá política que se escinde e afóndase logo máis ou menos, según a forza que teñan os sentimentos ou resentimentos patrióticos de calquera clas que sigan mantendo.

2 comarcals] comarcales. $1^{a}$ copia.

3 ainda que] pero. $1^{\text {a }}$ copia. 
O que desparece sempre é a lengua común como tal, trátese da coiné alexandrina ou do latín imperial.

Nesta ladeira histórica é onde deixamos estudiado o pasado do galego, dentro das circunstancias que puidemos precisar. $\mathrm{O}$ futuro parece que hai que albiscalo dende a ladeira oposta. Nas esperencias lingüísticas dos amoreamentos das pequenas comunidás.

Non podemos figuralo noutras circunstancias que nas que nel veñen operando desde fai cinco centos de anos e levan camiño de seguir en pe. Deixámolas señaladas atrás, pro volvémolas á repetir pra espoñer por enteiro o proceso.

Nunha comunidá limitada non pode haber un comprido desenvolvemento se non é sobre a base de relaciós de todo xénero coas comunidás veciñas, pasando dunha mau pra outra os tesouros das esperencias que sinifican as culturas dispersas $^{4}$ que estamos sempre á xuntare. Neste labor de parcería, un dos parceiros é o que leva a dianteira, pola súa situación xeográfica, pola súa forza económica, polo seu sino espansivo, polo que queira, e a súa lengua tórnase a divisa común deste comercio civilizador ó que non cabe cerrar as portas.

A sorte de avanzado na parcería da cultura hispánica caéulle a Castilla, despóis de ter pasado por Galicia e Cataluña, por demáis cerradas sobre si, nun preito en que pararse e tornar atrás, como saben os ascetas.

O proceso foi distinto según os tempos e está moi lonxe aínda de ser comprido. Hasta os nosos días poderíase resumir decindo que o castellano foi avante, representando o desenvolvemento histórico da Edá Moderna e que o galego se estancóu na espresión da vida rural, a onde aquél non chegaba, pero da que un día ou outro acabará por salir Galicia.

A partir do XIII, Castilla érguese coa hexemonía política. A lengua medra ó compás do imperio e vai cara a fixación literaria en códigos, historias, libros de recreo, cartas forales e toda clas de documentos. Siguen algún tempo os escritorios galegos dos mosteiros, concellos e catedrales, pero non todos. Cos grandes dinatarios de Castilla, que fan uso nos seus documentos da lengua da corte, van desparencendo pouco a pouco e os que quedan van dando entrada ós novos formularios diplomáticos. Hai quen quere competir co castellano e tenta reforzalo

${ }^{4}$ culturas dispersas] culturas e. $1^{\text {a }}$ copia. 
galego con traduciós como as das Sete Partidas, Os Milagres de Santiago, a Crónica Troyana. Pero os feitos iban de presa. Calaba a lírica dos Cancioneiros. Aparecía a cortesana italianizante. Os dirixentes políticos eran todos cortesanos. Móntanse en Galicia por todas partes colexios renacentistas pra as minorías direitivas. As máis escollidas van a Salamanca e Alcalá, onde se gastan xenerosamente as mellores enerxías de Galicia. A enseñanza renace nos mosteiros reformados; pero estes abandonaron as aldeas, en xeneral, e ademáis están rexidos por abades de outras terras e únense ó movemento castellanizante, ben apartados tras das altas cercas.

Despóis de todo eso, aparece, como é natural, unha minoría bilingüe que usa do castellano na súa función direitiva e do galego nas súas relacións íntimas con criados e caseiros. A lengua do país queda desta maneira reducida á espresión da vida tradicional, arcaica e mínima, que está fora das correntes vivas. A lengua da Eirexa e do Estado, a lengua de toda vida superior, dirixida polos señoríos, é o castellano. Sólo cando se supón que a Galicia labrega debe formar no coro dalgunha representación aparece o galego escrito. Pero nestes mismos casos, por de máis contados, sigue sendo a lengua labrega, na que non caben máis que as angueiras do diario vivir ó raso dos sucos.

Sin poñer na espresión ningunha intención de revengueita, sabendo ben que as cousas sucederon así porque así eran os tempos, debemos decir que o réxime de Galicia era o que máis se lle podería parecer a un réxime de colonia. Sin industria nin comercio, traballando terras sobre as que pesaban arrendos encadeados e amontoados os us sobre os outros, non cabía outra redención que a de chegar ó pe do altar falando castellano. Se había sorte, viña unha prebendiña e tras dela o subarrendo do foro de algunha ermida ou mosteiro abandonado para redemir os irmaos e sobriños. Estes, andando os anos, se se arrimaban a un bon padriño, podían chegar a unha estreita fidalguía pra a casa. Todo esto por verdadeiro milagre.

Os grandes dinatarios, no entanto, facían o que mellor sabían. Remediaban no que estaba na súa mau as grandes fames que se abatían sobre Galicia e levantaban as grandes eirexas e pazos que nos deixaron como herdanza, espello mentiroso dunha prosperidá que non conoceron os nosos antepasados.

Outra cousa sucede cando se chega a abrir a carretera de Madrí á Cruña. Chega por ela á Castilla un mar de labregos de Galicia e chega de Astorga e de 
León o primeiro comercio de verdá que tivemos, o que agatuñóu polas montañas, por vilas e aldeas, por feiras e feirós.

Foi este un momento de gran actividá lingüística. Nos vellos tempos — do XV ó XVIII - aparte a aparición da minoría bilingüe de que xa falamos, non sabemos hasta que punto puideron remover a tradición lingüística de Galicia as farándulas do teatro de Castilla, que non marraban nunca por Corpos. Este teatro pasaba das vilas ${ }^{5}$ ás aldeas, á cargo de xente do país, reducido ${ }^{6}$ á danzas, disputas e figuras ${ }^{7}$. Unha ${ }^{8}$ parte do folklore de hoxe quizaves proceda dos autos, entremeses e farsas de Castilla, así como moitas palabras, entre as que quixéramos anotar as de trasno, coca, cigarrón, irrio, demachiño, mázcara, nacen entón? ${ }^{9}$.

$\mathrm{O}$ sistema da lengua penso que non se alterase gran cousa.

A partir do XVIII deu cabo de sí esta situación. O bilingüismo que xuzgamos hasta certo punto inoperante sobre o sistema lingüístico mentras estivo reducido ás élites gobernantes, esténdese agora á un número meirande de xentes.

As novas xeneraciós tratan de superar o vivir tradicional, do que fan menos, no seu conxunto. Ven a súa liberación en todo o que a nova lengua sinifica, portadora de formas de vida universales ${ }^{10}$ e prestixiadas. Tratan polo tanto de aprendela. Emigran fora do país. Arremuínanse nas vilas. A lengua oficial deste xeito vai ganando como lengua común tódolos centros de cultura e adeministración que se van multiplicando, e chega ás familias burguesas.

E verdá que este bilingüismo non é tan radical en principio coma o primeiro. No caso do bilingüismo minoritario tratábase de xente con firme voluntá de falar a lengua oficial, ben dotada social e intelectualmente por outro lado, que podía, polo tanto, reproducila con gran fieldá. Neste segundo caso, os que fan uso dela, ainda ${ }^{11}$ que non lles marre a voluntá, veñen dunha categoría social inferior. Xente sin cultura, non chegan á asimilar a estrutura do castellano ${ }^{12} \mathrm{e}$ nace así unha lengua "criolla», bautizada co nome de "castrapo».

\footnotetext{
5 Corpos. Este teatro pasaba das vilas] Corpos e que pasaban das. $1^{\text {a }}$ copia.

${ }^{6}$ reducido] reducidas. $1^{\text {a }}$ copia.

7 figuras] firas. $1^{\text {a }}$ copia. Neste caso o A. corrixe unha errata mecanográfica.

8 Unha] Gran. $1^{\text {a }}$ copia.

9 mázcara, nacen entón.] mázcara e quizaves camello. $1^{\text {a }}$ copia.

10 universals] universales. $1^{\text {a }}$ copia.

${ }^{11}$ uso dela aínda] da lengua oficial, inda. $1^{\text {a }}$ copia.

${ }^{12}$ do castellano] da nova lengua. $1^{\text {a }}$ copia.
} 
O movemento ${ }^{13}$ non se estancóu, e, ó subir o nivel económico e cultural das nosas aldeas, gracias ós tempos e ós emigrados, o bilingüismo avanza tamén na súa forma máis radical. Síntese nos nosos días, cada vez ${ }^{14}$ máis, a necesidá do castellano, visto que o galego, pese ó rexurdir literario, como lengua de civilización ${ }^{15}$, sigue sendo a da vida labrega máis primitiva, superada de día en día. O comercio, a industria, a adeministración, a escola, a Eirexa, fortalezas sempre da lengua de Castilla, están agora máis presentes e autivas que nunca: Fixéronse donas dos recantos máis escondidos das serras e a súa aución é poderosa porque conta cos recursos todos da nova técnica ${ }^{16}$.

No punto e hora que estamos escribindo todo esto, o castellano é a lengua común de Galicia, a que todos entenden e a que todos falan ben ou mal cando queren ser entendidos por todos. Non cabe cerralos ollos a unha realidá.

Agora $^{17}$, ben. Dende este alto, ¿qué futuro se pode albiscar pra o galego ${ }^{18}$ ?

Se o proceso non se torce, o primeiro que se deixa prever é o bilingüismo xeneral, no que hoxe vive a gran Galicia emigrada. Cando esto suceda, que será cando Galicia se incorpore á onda de cultura e riqueza do seu tempo, quizaves ${ }^{19}$ se opere a lei do retorno, presente sempre nos seus destinos, e que Galicia volva á súa lengua, como vemos que volven os emigrados cunha devoción que nunca sentiran. $\mathrm{O}$ que non pode sere é que esta lengua seña a do pasado histórico, a que amamos nos cancioneiros.

Veremos agora por qué.

Os casos de bilingüismo son numerosos e están bastante ben estudiados. Según as circunstancias poden durar máis ou menos e chegar a moi distintos resultados. Se se trata dun bilingüismo total e perfeito, que é o que se dá nas comunidás que chegan á incorporación da cultura do seu tempo, o final é

\footnotetext{
13 mlovemento] movemento con todo. $1^{\text {a }}$ copia.

${ }^{14}$ Síntese nos nosos días, cada vez] Síntese cada vez. $1^{\text {a }}$ copia.

${ }^{15}$ de civilización] do comercio humano. $1^{\text {a }}$ copia.

${ }^{16}$ técnica] técnica, e o galego non conta máis que co amor de moi poucos e o analfabetismo dos máis. $1^{\mathrm{a}}$ copia.

${ }^{17}$ Agora] E agora. $1^{\text {a }}$ copia.

${ }^{18}$ galego] gallego. $1^{\text {a }}$ copia.

${ }^{19}$ quizaves] eu espero que. $1^{\text {a }}$ copia.
} 
sempre a absorción da lengua local ${ }^{20}$, con máis ou menos consecuencias lingüísticas, que non cabe determinar, pola lengua común ${ }^{21}$.

O proceso parece vir determinado por dous principios da lingüística xeneral. $1^{\circ}$. O manexo simultáneo de dúas lenguas leva a fixar nunha delas as estruturas da outra. $2^{\circ}$. Esto provoca un río de alteraciós na lengua local a favor da lengua común (M. Schcherba).

Esto parece estar en contradición co que vemos tódolos días: os galeguismos das nosas xentes que falan en castellano, na fonética, no vocabulario e nas costruciós, e as estruturas típicas dos nosos escritores en castellano, tanto as coscentes de Valle Inclán, poño por caso, como as incoscentes de outros moitos, das que se decatan os castellanos nativos. A verdá é que non é así. Os galeguismos incoscentes débense a que o estado de bilingüismo inda non é acabado e os de Valle Inclán esprícanse como recursos estéticos. No noso suposto, que queremos manter por amor a Galicia, as consecuencias son as anunciadas. O galego histórico irase desfacendo pouco a pouco. Sin que haxa nada pra remedialo, a nosa lengua preséntase na súa fonte tal como é, chea de variantes, libérrima de estruturas. $\mathrm{O}$ que a fala pensa que nunca peca en contra dela, porque as novas estruturas que lle impón son correctas na lengua común. Esto non pasa aínda hoxe, pero pasará co tempo.

A lengua oficial, polo contrario, está defendida polo feito de ser lengua común, hábito renovado desde neno pola escola e a sociedá, o xornal e o documento, a radio e o cine. Os individos verdadeiramente bilingües non impoñerán nunca ó castellano unha estrutura galega. Facelo sinifica cultura inferior e están subconscentemente sobre aviso. Frente ó galego, indefenso de normas e cheo de variantes, non hai nada que lles impida usar das estruturas castellanas que a ninguén sorprenden. Esto é xa tan verdá que hai moitos libros galegos nos que, aparte o vocabulario, todo o demáis é castellano. $\mathrm{Ni}_{\text {unha }}{ }^{22}$ sola estrutura sintática galega se atopa neles. $\mathrm{O}^{23}$ mismo vocabulario non pasa de ser tradución de

\footnotetext{
${ }^{20}$ a absorción da lengua local,] a incorporación da lengua común,. $1^{\text {a }}$ copia.

${ }^{21}$ lingüísticas, que non cabe determinar, pola lengua común] lingüisticas que non cabe determinar. $1^{\text {a }}$ copia.

${ }^{22} \mathrm{Ni}$ unha] Ni'unha. $1^{\text {a }}$ copia.

$\left.{ }^{23} \mathrm{O}\right]$ E o. $1^{\text {a }}$ copia.
} 
outra lengua, como é natural que seña ${ }^{24}$. Se o galego é unha lengua rural, e esto é ben certo, as súas palabras hai que enchelas de viño novo sempre que queiramos espresar con elas outras cousas. E esto é unha violencia que pode sufrir unha que outra palabra, pero non toda unha lengua.

¿Acabará, según esto, o galego por fundirse coa lengua común? ${ }^{25}$

As vitorias son sempre á medias. Deixamos dito que as lenguas nin nacen nin morren. Cando o galego que hoxe falamos teña pasado, como pasou o latín de San Martiño, é seguro que Galicia vivirá, meirande ca nunca, multiplicada polo mundo adiante, como parece ser o seu sino.

Sin meternos nas consecuencias lingüísticas que leva consigo a asimilación dunha lengua por outra, e que nalgúns casos foi nada menos que a aparición dunha nova lengua, podemos aventurar que a Galicia do futuro, para a que eu gardo tódalas miñas esperanzas ${ }^{26}$, non será unha Galicia muda. A lengua que fale será a súa lengua.

A Galicia que se espalla polo mundo enteiro sin perdelo sentimento da súa unidá patrucial, se un día se esquence da lengua dos vellos labregos non será por desleigamento, senón por un imperativo de futuro. Cando eso suceda xa terá ${ }^{27}$ dado a volta ó mundo a canción que estrene a lengua universal e viaxeira da nova Galicia. Ben mirado, non será outra que a que hoxe falamos nin será outra que a que fundiron romanos e nativos ó longo das estradas e corredoiras, porque será a lengua de Galicia que non morre, agromada outra vez e outra vez florecida en nova primavera.

Sabemos que sorprenderá que señan estas as conclusiós de quen leva toda a vida escribindo en galego e pensa aínda escribir nesta lengua as palabras verdadeiras que se deixan pra cando maduran os corazós.

A lealtá con que as pensamos líbranos de todo remordemento.

\footnotetext{
${ }^{24}$ seña.] seña, por outra parte. $1^{\text {a }}$ copia.

25 común?] común? Non temos medo nin sentimento en decir que sí, sempre que se entenda que o decimos co meirande amor que se lle pode ter a unha lengua, coa voluntá firme de mantela e cultivala como a reliquia máis preciada da nosa historia, coa esperanza máis firme de que tras ela ha de vir outra coma tras dos solpores ven a aurora. $1^{\text {a }}$ copia.

26 esperanzas,] esperanzas, dedicándolle a ésta os meus esforzos,. $1^{\text {a }}$ copia.

27 Vid. infra n. 28.
} 
O que nos dá congoxa é que poidan ser mal interpretadas. Que pense alguén que o galego xa rematou a súa xornada e que non queda máis por facer que limpar o mundo das dúas arruínas.

Nada máis bárbaro que semellante pensamento. Pra velo non hai máis que trasladalo ás outras creaciós históricas, como as obras de arte, os costumes, as crencias. As estruturas románicas están máis fora das leises da costrución de hoxe, teñen ben menos de funcional, son, sobre todo, ben menos galegas que a nosa lengua. Con todo e con eso, non se pensa en arrasar as que os tempos convertiron en arruínas, como é lei de vida, nin moito menos as que aínda siguen en pe. Nunca contaron, polo contrario, coa devoción con que hoxe contan. E cando de levantar unha nova eirexa — de seguir unha tradición-, non se ten unha solución mellor que as que levóu ó seu cume comprido a Galicia do XII ${ }^{28}$.

Este ten que $\operatorname{ser}^{29}$ o pensamento que presida a autitú ${ }^{30}$ frente ó galego. Como estaría fora de punto convertir o románico en canon da presente e futura costrución galega en xeneral, así o estaría tratar de convertir o galego ${ }^{31}$ en medio único de espresión da nova e futura Galicia, que non cabe, polo seu ben, nas vellas formas nutricias, e que, lonxe ${ }^{32}$ de ser unha reliquia histórica, está en trance de convertirse en brilante protagonista de novos destinos.

Pero, detrás desta, queda a Galicia histórica, da que non cabe esquencerse $\mathrm{e}^{33}$ porque sin ela non pode vir outra. E a Galicia histórica cantóu e sufréu en galego, neste galego que morre xenerosamente pra que Galicia viva. Non se pode ${ }^{34}$ renunciar ó pasado sin renunciar ó futuro, e a lengua é a sorte máis rica do pasado $^{35}$. O feito de estar nun momento de tránsito, aparentemente de morte,

\footnotetext{
${ }^{28}$ A Galicia que se espalla polo mundo enteiro sin perdelo sentimento da súa unidá patrucial, se un día se esquence da lengua dos vellos labregos non será por desleigamento, senón por un imperativo de futuro. Cando eso suceda xa terá] Este texto está cancelado na segunda copia, pero este foleo o e seguinte están rachados, conservándose só a primeira parte do mesmo; cando se recupera o novo folio, remata coa frase «a Galicia do XII». Non hai datos para decidir onde remata a cancelación e se había ou non outras modificacións; por esta razón, copio enteira a primeira copia.

29 ser] ser tamén. $1^{\text {a }}$ copia.

30 a autitú] a nosa autitú. $1^{a}$ copia.

31 o galego] a nosa lengua. $1^{\text {a }}$ copia.

${ }^{32}$ nutricias, e que, lonxe] nutricias e lonxe. $1^{\text {a }}$ copia.

33 non cabe esquencerse] non debemos esquecernos. $1^{\text {a }}$ copia.

${ }^{34}$ Non se pode] Non podemos. $1^{\text {a }}$ copia.

${ }^{35}$ pasado] noso pasado. $1^{\text {a }}$ copia.
} 
é a mellor razón para sentir todo o que ten de legado pío. Ni unha palabra das que cada día morren nos labios dos vellos ${ }^{36}$, para deixar o seu lugar ás que son vida nos dos mozos, debera quedar sin o seu debido e as súas honras.

Cando en Galicia non se fale o galego da tradición, é seguro ${ }^{37}$ que se estudiará con amor nas universidás ${ }^{38}$. E non haberá outro galego que o que quede dunha ${ }^{39}$ pobre literatura e o que se adiviñe na lengua que profetizamos ${ }^{40}$.

$\mathrm{O}$ que a lengua tradicional de Galicia esteña a punto de trasformarse non é razón tampouco de que se abandone o seu cultivo tanto no medio familiar como nas obras de creación literaria. Así como non se atopa en Galicia unha solución mellor pra unha eirexa e pra un prazo que as do románico e o barroco, cando románico e barroco son formas caducadas en xeneral, así tamén, pra espresión do ser íntimo de Galicia, non hai, hoxe por hoxe, outra lengua que o galego. Esto é o que deben pensar ben, sobre todo, os nosos poetas, posto que a poesía ama sempre as lenguas vellas, e non sin razón. Pra o resto, o proceso é natural ${ }^{41}$.

A misión do verdadeiro poeta ven revelada por unha forza interior que o leva a decir a súa verdá conforme á ditados purísimos, nos que non entra fama nin proveito. Esta forza pode manar de moitas fontes, que a vida é longa e ancho é o mundo.

As caraiterísticas desta lengua, <o seu ser mismo >, son as que non cabe determinar, achegados como está ó porvir ${ }^{42}<$ económico social e> político. Unha cousa é certa: non cabe esperar un glorioso ${ }^{43}$ futuro pra as lenguas que ${ }^{44}$ non son portadoras dun vivir $<$ total superior e independente ${ }^{45}$ das xentes que as falan e que, polo tanto, están privadas do comercio universal ${ }^{46}$.

\footnotetext{
${ }^{36}$ nos labios dos vellos] cos nosos vellos. $1^{\text {a }}$ copia.

37 é seguro] eu sei de certo. $1^{\text {a }}$ copia.

38 nas universidás] nas nosas universidás. $1^{\text {a }}$ copia.

${ }^{39}$ dunha] da nosa. $1^{\text {a }}$ copia.

${ }^{40}$ profetizamos] profetizamos. E caerá sobre os galegos outra vergonza máis. $1^{\text {a }}$ copia.

${ }^{41}$ razón. Pra o resto, o proceso é natural.] razón. $1^{\mathrm{a}}$ copia.

${ }^{42}$ seu porvir: cancelou seu, e ameceu: das xentes que a(s) falan, que substituíu por de Galicia. Rematou por prescindir deste parágrafo.

43 grorioso: substituíu a ningún.

${ }^{44}$ lenguas que] escribira primeiro: lenguas das naciós sin vida realmente propia que, que cancelou.

45 dun vivir total superior e independente] substitúe a: do vivir superior.

46 universal] Escribeu e cancelou: ¿Como podemos facer pra poñer neste pe o galego? Faltan moitas circustancias pra poder supoñer neste pe o galego. Pero longa é a vida.
} 
O galego está reconocida como unha gran lengua poética. Pero o porvir non é das lenguas poéticas, como se viu na vella Grecia e na Edá Media de Europa, senón das que ${ }^{47}$ levan no seu seno a vida fervorosa de cada día, as suas loitas, enventos e ideas.

¿Cabralle algún dia a sorte ${ }^{48}$ ô galego de ser portador de tales novas ${ }^{49}$ ?

O camiño [e] longo, pero ¿quen sabe?

Sólo o que mane ${ }^{50}$ da fonte máis fonda de Galicia virá en galego. Pero, neste caso, non cabe calar a doce voz antiga sin perderse. O ser íntimo de Galicia, como o de calquera outra xente, non se deixa apreixar se non é na maraña da propia lengua. Nela vive entrañado e vivo, mellor que en ningunha outra creación do espíritu nacional.

Se non é así, non cabe tampouco finxir esa voz e falar de fala mudada. O poeta ten que ser fiel a sí mismo. Mal pode escribir en galego quen non refixo esta lengua ${ }^{51}$ según as formas vivas da tradición, cando o que escribe pretenda ser espresión pura do seu mundo personal. As lenguas adeprendidas nas gramáticas e diccionarios e calcadas sobre outras lenguas son medios de expresión sin alma. Prestan o seu servicio, pero non ós poetas.

Despóis de anunciar tan cativos destinos ó galego como lengua de cultura e de porvir político, quero rematar aventurando pra ela un gran futuro como lengua da poesía. Penso pra facelo así no día en que das nosas aldeas poidan salir moitos rapaces que cheguen á ser donos dunha cultura verdadeiramente superior. Esto sucederá cando queiran volver á ela como á un recordo amigo, sin que lles encolla o ser o pesadelo de pasadas miserias sin que lles ate o pensamento a superación de tantos problemas coma hoxe aburan as almas.

Daquela oirán de certo os poetas galegos a doce voz antiga. E compriráse o destino desta lengua que nacéu para lengua de cancioneiro.

Dios nos deixe vir unha Galicia rica, como quería Curros Enríquez, e o demáis irá vindo polo seu pé.

\footnotetext{
47 das que] O A. escribira: das portadoras da.

48 a sorte] Escribira: esta sorte. Coido que despois de galego escribiu a sorte, que cancelou por razóns evidentes.

${ }^{49}$ novas] Cancelou o que viña despois: «E quen sabe / E non hai duda /».

${ }^{50}$ mundo (....) Sólo a que mane] mundo. Solo as que manen. $1^{\text {a }}$ copia. Nestes parágrafos amecidos polo autor a man, poño entre ángulos o amecido polo propio autor na súa primeira redacción.

${ }^{51}$ lengua] lengua desde neno. $1^{\text {a }}$ copia.
} 